THE question of the influence of wind and rain in valley formation is discussed by Herr Rucktäschel in a short memoir contributed to the current number of Petermann's Mitteilungen, abstracted in the Proceedings of the Royal Geographical Society. The author, who has been pursuing his studie; in Saxony and elsewhere, ascribes the "one-sidedness" which is observable in so many of the river valleys of Saxony to the action of rainy winds, in the absence of considerations arising from the configuration or composition of the soil. It has been observed that, in the case of most streams in this region flowing through soft sandstone, conglomerate, and diluvial soils, the east, north-east, or south east bank presents a steep slope, while the opposite shore is flat. The cause is, according to Herr Ruckläschel, to be found in the action of the prevailing south-west, west, and north-west winds, which, heavily charged with rain, precipitate themselves almost at right angles upon the eastern sloping bank of a stream, washing away the soil in much greater quantity than from the western bank, and thus producing the onesidedness referred to. Similar phenomena have been observed in some of the river valleys of Prussia and Bavaria. The author lays down the following conditions as necessary for the production of these effects by the westerly rain winds: (I) the soil must be composed of some loose or soft substance, (2) the valley'must be eroded to a certain depth, (3) the volume of water in the stream must not be too great in proportion to that washed down the banks. For these reasons the phenomena can occur, as a rule, only along the smaller rivers, a large river; by the force of its own current, shapes its banks, and the influence of the prevailing rain winds is not so noticeable. Herr Rucktäschel visited England last summer to carry out researches there, but was unable to find any river-valleys suited for his purpose.

IT is reported from Hong Kong that the expedition of Mr. Rosset in the as yet unexplored districts of Annam, Cochin China, Cambodia, Siam, and the Laos States has been concluded. Much danger and many difficulties were encountered, but the result has been excellent, and Mr. Rosset will take back with him to Europe a valuable collection illustrative of the ethnology of the regions he has traversed. The journey was divided into three sections. The first comprised the Mekong River, the Chane and Bang-Came Rivers, to Stung-treng, in Siam, IO4 $^{\circ}$ to IO $^{\circ}$ long. and $13^{\circ}$ to $14^{\circ}$ lat. In this section the tribes of the Brouns or Bruns, the Kongs, and the Bennongs, were visited and studied. The second section of the journey as projected was from the mouth of the River Dongnai in Cochin China up to the frontier, covering the country between $104^{\circ}$ and $106^{\circ}$ long., and $1 I^{\circ}$ and $12^{\circ}$ lat., the special object of study being the ethnology of the Mois tribes. It was found, however, that the route was impracticable, the heavy rains and thickness of the jungle preventing the progress of the caravan, and the expedition was obliged to make a detour into the mountains of Binthuan. The third section of the journey again followed the Mekong River to Kratse, from thence branching east and north-east to the coast of Annam. Approaching Bung $U$ the expedition followed a north-easterly direction to $13^{\circ}$ lat. About 25 kilometres southeast of Kratse the River Pree Sé was passed, and the same river was crossed three times in the journey north-east to the coast; also a tributary river called the Sala. In this section the tribes of the Bennongs, Sliengs, Nhongs, and Ahongs were studied.

\section{THE TEACHING OF SCIENCE.}

IN a Report presented to the Bath meeting the Committee gave an account of the replies they had received to a letter addressed to the head masters of schools in which elementary chemistry is taught. In this letter the Committee had asked for a report on the chemical teaching, and also for a statement as to the inethods which had been found to render the teaching most effective as mental training. In commenting on these replies the Committee pointed out that the evidence which had been collected was conclusive in showing that much of the teaching of elementary chemistry is far from satisfactory, and needs to be considerably modified if it is to effect that valuable mental discipline which science teaching can afford.

${ }^{1}$ Report of the Committee, consisting of Prof. H. E. Armstrong, Prof W. R. Dunstan (Secretary), Dr. J. H. Gladstone, Mr. A. G. Vernon Harcourt, Prof. H. McLeod, Prof. Meldola, Mr. Pattison Muir, Sir Henry E. Roscoe, Dr. W. J. Russell (Chairman), Mr. W. A. Shenstone. Prof. Smithells, and Mr. Stallard, appointed for the purpose of inquiring into and reporting upon the present methods of teaching Chemistry.
The Committee are convinced that the high educational valıe of instruction in physical science has never been exhibited to its full advantare in most of our educational institutions. Nevertheless there exists already a considerable body of experience which proves that there is no more effective and attractive methorl of training the logical faculties than that which is afforded by a properly arranged course of instruction in physical science; by no other means are the poweis of accurately ascertaining facts, and of drawing correct inferences from them, so surely developed as they are by the study of this subject.

Since the last meeting the Committee have been actively engaged in discussing the lines which a course of elementary instruction in chemistry should follow. The Committee were the more inclined to offer suggestions of their own, since they had learnt from the replies made to their letter of last year, by teachers in many of our well-known schools, that not only is the necessity for the adoption of improved methods fully recognized, but that teachers are anxious to receive advice and assistance in introducing them.

It cannot be too strongly insisted that elementary physical science should be taught from the first as a branch of mental education, and not mainly as useful knowledge. It is a subject, which when taught with this object in view, is capable of developing mental qualities that are not aroused, and indeed are frequently deadened, by the exclusive study of languages, history, and mathematics. In order that the study of physical science may effect this mental education, it is necessary that it should be employed to illustrate the scientific method of investigating Nature, by means of observation, experiment, and reasoning with the aid of hypothesis; the learners should be put in the attitude of discoverers, and should themselves be made to perform many of the experiments. The lessons ought to have reference to subjects which can be readily understood by children, and illustrations should be selected from objects and operations that are familiar to them in every-day life. Chemistry is particularly well adapted for affording this kind of instruction, and the Committee are of opinion that a course which is mainly chemical will be most useful in developing logical habits of thought.

Chemical inquiry involves, however, the use of various physical processes, and these are themselves of great value from the point of view from which the instruction is being given. It is also of great importance that the learners should become acquainted with the characteristic instrument of physical science, viz. measurement, and therefore quantitative processes should be largely made use of.

Having agreed as to the general principles on which a scheme of elementary instruction in chemistry should depend, the Committee gladly accepted the offer of Prof. Armstrong to draw up an account of such a scheme in sufficient detail to serve as a guide to those who have to provide such teaching. Wilhout pledging themselves to accept all its details, the Committee consider that the scheme which Prof. Armstrong has prepared is in general accordance with their views as to what should constitute a course of elementary instruction in physical science.

With regard to the manner in which the scheme should be carried out, the Committee wish to lay stress on the following. points. In order that the plan shall produce its full educational effect, the instruction should be commenced at an early age, and be extended to every child in the school. They do not desire to bring forward physical science as a substitute for any of the other principal subjects of study, but they ask that like these subjects it should be looked upon everywhere as a necessary part of education, and that it should receive a due share of the time devoted to school work. It is well known that at present science-teaching does not generally receive as much time and attention as is given to other studies. This was made clear in the Report of the Committee last year. It will be necessary to allot more time to the subject, and to employ a greater number of teachers. A teacher should not be required to give practical instruction to more than from fifteen to twenty pupils at one: time, although the classes at lectures and demonstrations might be somewhat larger.

While the scheme now proposed may involve the employment of a larger number of teachers of natural science, on the other hand fittings and apparatus of the simplest description are ali that will be absolutely needed, and the cost of maintenance will be relatively small.

The Committee are aware that the course of instruction now suggested is not in conformity with the present requirements of 
examining bodies. Its general adoption must therefore depend on their co-operation.

\section{Suggestions for a Course of Elementary Instruction in Physical} Science, drawn up by Prof. Armstrong.

Although the Committee is ostensibly charged to report as to methods of teaching chemistry, chemistry pure and simple is not what is required in schools generaliy, and therefore the Committee must be prepared to take into consideration and make recommendations as to a course of instruction preliminary to the natural science course proper, which in their opinion affords the most suitable and efficient preparation for later natural science studies.

After the most careful consideration of the question during at keast ten years past, and after long holding the opinion that chemistry as usually understood is not the most suitable science subject for school purposes, I am now of opinion that a course which is mainly chemical is not only the best but also the only one possible if we are to secure all the objects aimed at in introducing science teaching into schools. Those objects are essentially : to train boys and girls to use their brains; to train their intelligence; to make them observing and reasoning beings, accurate observers, and accurate thinkers; to teach them to experiment, and that, too, always with an object-more frequentiy than not with what may be termed a logical object-not for mere descriptive purposes; to gradually inculcate the power of "doing," on which Charles Kingsley has laid so much stress, and which undonbtedly is the main factor of success in dife. It can scarcely be gainsaid that through chemistry more than through any other branch of natural science it is possible to give precisely that kind of "practical" training so requisite at the present day, because the student is able to ascertain by experiment what are the exact facts, and thus to arrive independently at an explanation, whereas in the case of other sciences more often than not the explanation of necessity has to be given by the teacher.

Chemistry as usually taught loses greatly in educational value because pupils are told, more often than not, that "so and so is the case," instead of being taught how it has been found out that such is the case; indeed, that which has to be proved is usually taken for granted. Practical chemistry has hitherto, as is rule, been interpreted to mean the preparation of a few gases, \&c., and the analysis of simple salts. Much useful information may be and is occasionally imparted during the performance of exercises of this kind, but the tendency undoubtedly is for analysis to degenerate into a mechanical drill, and, looking at the question from the practical point of view, and considering what is the general outcome of such teaching, probably we are bound to agree that the results thus far obtained are usually unsatisfactory. The difficulty, however, is to devise a course sufficiently simple both in conception and when carried into practice the cost of which is not too great; but with respect to this item of cost the Committee has to make clear to parents and teachers the claim of natural science to a fair and proportionate share of the total expenditure, which certainly has never yet been granted to it. By the introduction of such studies into the school course, a set of faculties are trained which it is allimportant to develop, but which hitherto have been allowed to remain dormant, if not to atrophy, through neglect, and which, it is admitted by all competent authorities, cannot possibly be developed by any amount of attention paid to literary and mathematical studies. It is often not sufficiently clearly stated or understood that the advocates of natural science studies have no desire to displace any of the traditional subjects from the school course, and that all that they ask for is a fair share of the child's time, attention, and brains- -a share proportionate to the effect which such studies can demonstrably produce in developing the mental faculties of the individual : that, in fact, natural science claims to co-operate and in no sense puts in an appearance as a rival.

STAGE I.-Lessons on common and familiar objects.

The first stage of instruction must be one of simple objectlessons, but these should have an intimate relation to the child's surroundings, and should be made the pegs on which to hang many a tale. Probably the most satisfactory and practic 1 l mode of commencing is to get children to draw up lists of familiar and common objects under various heads, such as

Natural objects.

Things used in building construction.
Things from which household furniture is made or which are in daily use.

Things used as clothing.

Food materials.

The children should be induced to describe these from observation as far as possible; to classify them according to their origin into mineral and animal and vegetable or organic ; and occasion should be taken at this stage to give by means of reading lessons and demonstrations as much information as possible about the different things, their origin, how made, and their uses. It is obvious that in this way a great deal of geography and natural history (Naturkunde) might be taught in an attractive manner. Geikie's "Science Primer on Physical Geography" is the type of book which may be worked through with great advantage at this stage.

\section{STAGE II.-Lessons in mcasurement.}

This stage should be entered upon as soon as children have learnt the simple rules of arithmetic, and are able to add, subtract, multiply, and divide, and to use decimals.

I.ineal measurements may be first made, using both an English foot-rule with the inch subdivided in various ways and a metric rule subdivided into millimetres. In this way the relation of the two scales is soon insensibly learnt.

Measurements of rectangular figures and the calculation of their areas may then be made.

After this the use of the balance may be taught, and the relation between the English and French systems may be learnt by weighing the same objects with the two kinds of weights. Use may then be made of the balance in determining the areas of irregular figures by cutting out rectangular and irregular figures from the same cardboard or thin sheet metal, and weighing these, \&c.

Solid figures are next studied : a number of cubes made from the same wood having been measured, their volumes are then calculated, and the results thus obtained are compared with those which are obtained on weighing the cubes. The dimen. sions and weights of cubes made from different woods or other materials are then ascertained, and thus it is observed that different materials differ in density. 'The study of the relative density of things generally is then entered upon. The ordinary method is easily learnt and used by children, a suitable bottle being provided by filing a nick down the stopper of a common two-ounce narrow-mouth bottle; it may then be shown that the same results are obtained by the hydrostatic melhod of weighing in air and water, and it is not difficult to lead children to understand this latter method after they have determined the heights of balancing columns of liquids, such as turpentine, water and saturated brine, of which they have previously ascertained the relative density. These hydrostatic experiments are of value at a later stage in considering the effects of atmospheric pressure.

By determining the dimensions of a cube and the weight of the water which it will displace, an opportunity is afforded to point out that if the results are expressed in cubic centimetres and grammes respectively there is a practical agreement between the numbers, and hence, to explain the origin of the metric system of weights and the relationship between its measures and weights; the irrationality of the Ehglish system may then be explained.

The relative densities of a large number of common substances having being ascertained, the results may be tabulated and then the value of the data as criteria may be insisted on; as an illustration of their value, quartz, flint, sand, and gravel pebbles may be selected. The children having determined their relative densities, the agreement between the results may be pointed out and the identity of the material explained. By drawing perpendiculars corresponding in height to the densities of various substances, a graphic representation is obtained which serves to bring out the value of the graphic method of representation.

A very valuable exercise to introduce at this stage is based on the well-known fact that in certain conditions of the atmosphere things appear moist; a muslin bag full of seaweed may be hung up under cover but freely exposed, and may then be weighed daily at a given time; simultaneously the state of the weather, direction of the wind, the height of the barometer, and the wet and dry bulb thermometer may be noted; on tabulating the results, and especially if the graphic method be employed, the variations and their relationship will be noticeable.

The thermometer, having thus become a familiar instrument, 
may be used to examine melting ice and boiling water ; the construction of both the Centigrade and Fahrenheit thermometer may then be explained, and the effect of heat on bodies made clear. The density of ice and of water at varicus temperatures may then be determined, a Sprengel tube-which is easily made -being used for warm water; the bursting of pipes in winter, the formation of ice on the surface of water, \&c., may then be explained. Afterwards simple determinations of the heat capacity of a few metals, \&c., and of the latent heat of water and steam, may be made in accordance with the directions given in a book such as Worthington's "Practical Physics."

\section{STAGE III.-Studies of the effect of heat on things generally; of their behaviour when burnt.}

As it is a matter of common observation that heat alters most things, the effects of heat on things generally should be studied; in the first instance qualitatively, but subsequently, and as early as possible, quantitatively. Bits of the common merals may be heated in the bowl of an ordinary clay pipe plunged into a clear place in any ordinary fire, or in such a pipe or a small iron spoon over a gas flame. The difference in fusibility is at once apparent, and in the case of metals like iron and copper it is noticeable that although fusion does not take place, a superficial change is produced; the gradual formation of a skin on the surface of fused lead and tin is also easily perceived. Observations like this become of great importance at a later stage, and indeed serve to suggest further experiments: this is a point of special importance, and from the beginning of this stage great attention should be paid to inculcating habits of correct observation ; the effect should first be recorded by the pupil, the notes should then be discussed and their incompleteness pointed out, and they should afterwards be re-written. The fusibility of substances which are not affected when heated in the tobacco pipe may be tested by heating them with a Fletcher gas blow-pipe on charconl; and by heating little bits of wire or foil in such a flame it is easy for children to discover the changes which metals undergo when burnt, especially in cases such as that of zinc or copper or iron.

The further study of the effects of heat should be quantitative, and may well commence with water. It being observed that water disappears on heating, water may be put into a clock glass or glass dish placed on a water bath (small saucepan); it evaporates, and it is then observed that something is left. A known quantity of water by weight or volume is therefore evaporated and the residue weighed. This leads to the discovery that water contains something in solution. The question then naturally arises, What about the water that escapes? so the steam is condensed and the distilled water evaporated. The conception of pure water is thus acquired. An experiment or two on dissolution -using sait and sugar-may then be introduced, a water oven or even an air oven (a small Fletcher oven) kept at a known temperature being used, and the residue dried until the weight is constant. Rain and sea-water may next be examined; the results afford an opportunity of explaining the origin of rain and of accounting for the presence of such a large quantity of dissolved matter in sea-water. Then the various common food materials may be systematically studied, commencing with milk; they should first be dried in the oven, then carbonized and the amount of char determined, then burnt and the percentage of ashes determined. A small platinum dish, I 5 to 20 grammes in weight, is required for these experiments, and a gas mufle furnace is of the greatest use in burning the char and in oxidizing metals. In addition to the discipline afforded by such experiments a large amount of valuable information is acquired, and the all-important fact is established that food materials generally are combustible substances. Afterwards mineral substances are examined in a similar manner, such as sand, clay, chalk, sulphur, \&c., and then metals such as lead, copper, tin, and iron may be studied; their increase in weight is in striking contrast to the inalterability of substances like sand and salt, and the destruction of vegetable and animal substances. Chalk, from which lime is made by burning, is found to occupy a middle position, losing somewhat in weight when strongly heated. The exceptional behaviour of coal among mineral substances, and of salt amon food materials, is shown to be capable of explanation, inasmuch as coal is in reality a vegetable and salt a mineral substance; but sulphur remains an instane of exceptional behaviour requiring explanation. It is not exceptional in being combustible, as metals like magnesium and zinc are combustible, but in affording no visible product. The smell of burning sulphur, however, serves to suggest that perhaps, after all, there is a something formed which is an invisible substance possessed of an odour, and then follows quite naturally the suggestion that perhaps in other cases where no visible or perceptible product is obtained-as on burning charcoal, for instance-there may nevertheless be a product. Whereas, therefore, in Stage I. the pupil will have learnt to appreciate the existence of a great variety of substances, and will have gained the power of describing their outward appearance more or less fully; and in Stage II. having learnt how to measure and weigh, will acquire the habit of determining by measurement certain properties of substances, and will thus be in a position to express in exact terms the kind of differences observed ; in Stage III. the pupil will be led to see that profound changes take place on burning substances, and that these changes involve something more than the destruction of the things burnt. The foundation is thus laid for the study of change, i.e. chemical studies proper.

\section{STAGE IV.-The problem stage.}

Many of the changes observed in the course of the experiments made in Stage III. might be examined and their nature determined, but the best to take first is a very familiar case, that of the rusting of iron.

ProblexI I. To determine what happens when iron rusts.The pupil must be led in the first instance to realize that a problem is to be solved, and that the detective's method must be adopted and a clue sought for. It is a familiar observation that iron rusts, especially when wet ; what happens to the iron, why does it rust, is the iron alone concerned in the change? No information can be gained by looking at it-perhaps the balance which has brought to light so much in Stage III. may be of service, so the iron is allowed to rust in such a manner that any change in wejght can be observed. A few grammes of iron filings or borings are put on to a weighed saucer or clock glass along with a bit of stiff brass or copper wire to be used as a stirrer; the iron is weighed, then moistened and exposed under a paper cover to keep off dust, preferably in a warm place ; it is kept moist and occasionally stirred. After a few days it is dried in the oven and then weighed. The weight is greater. Something from somezuhere has been added to the iron. Thus the clue is gained. Where did this something come from? The fact that when a tumbler, for instance, is plunged mouth downwards into water the water does not enter, and that on gradually tilting the tumbler to one side something escapes-viz. air-at once affords a demonstration of the presence of air in the space around us. The iron rusted in this air, but was kept moist, so it may have taken up the something from either the air or the water. To ascertain whether the air takes part in the rusting, some iron borings are tied up in a bit of muslin and the bag is hung from a wire stand placed in a (jam) pot full of water and a so-called empty (pickle) bottle, which in reality is full of air, is inverted over the iron; in the course of a few hours, as the iron rusts, the water is observed to rise until it occupies about one-fifth of the jar (determined by measuring or weighing the water); the something added to the iron during rusting appears therefore to come from the air, and the all-mportant fact is thus discovered that the rusting is a change in which not the iron alone, but also the air, is concerned. The experiment is several times repeated, fresh iron being used with the same air and the same iron put in succession into fresh portions of air, but the same result is always obtained: whence it follows that whatever it is in the air which takes part in the rusting, the air as a whole is not active. The changes previously observed to take place when iron, copper, lead, zinc, \&c., were heated in air, are then recalled; as the metals were found to increase in weight, it would appear probable that in these cases of change also the air was concerned.

These results at once suggest the question, What is air? So much having been learnt by studying the change which iron undergoes in rusting, other changes which happen in air therefore are next studied.

PROBLEM II. To determine the nature of the changes which iake place on burning substances in air.-.'The use of phosphorus is introduced by reference to a match. Phosphorus is then burnt under a bell jar over water and the result noted : the disappearance of some of the air again shows that the air is concerned. The fact that phosphorus smokes when taken out of the water in which it is always kept suggests that some change is going on, so a stick of phosphorus is exposed in air as in the previous experiment with iron: soon one.fifth has disappeared, and the phosphorus then ceases to smoke. The 
quantitative similarity of the two results suggests that iron and phosphorus behave alike towards air, and vice versit, and serves to confirm the ide a that some constituent of the air present only to the extent of about one-fifth is active. But nothing is to be taken for granted, so iron is exposed in the phosphorus-air residue and phosphorus in the iron-air residue : as no change occurs, there is no room left for doubt. Recalling the experi ments in which various metals were burnt in air, in order to determine whether in these cases the same constituent of the air was concerned in the change, air from which the active constituent has becn removed by means of phosphorus is passed through a heated tube containing bits of the metals : no change is observed, so it is evident that as a rule, if not always, one and the same constituent of air is concerned. The experiments with iron and phosphorus, althongh they show ihat the air is concerned in the changes which are observed to take place, do not afford any information whether or no the water which is also present is concerned in the change. Phosphorus is therefore burnt in a "Florence" flask closed with a rubber stopper : on removing the stopper under water some water enters, and by measuring this and the amount of water which will fill the flask the same result is obtained as in the previous cases. To be certain whether in this case anvthing enters or escapes from the flask it is weighed before and after the phosphorus is burnt. There is no change in weight. But does nothing escape? Yes, much heat; whence it follows that heat is not material-that, although some of the air disappears, it is merely because it has become affixed to or absorbed by something else. This has been proved in the case of the rusting iron and the burnt metals. To obtain indisputable evidence in the case of the phosphorus this is burnt in a current of air in a tube loosely filled with asbestos to retain the smoke: the weight is found to increase. The observation that the phosphorus ceases to burn after a time suggests the introduction of a burning taper into the residue left by iron, \&c. ; it is found to be extinguished. Then a candle ind subsequently a gas flame may be burnt in a bell jar full of air over water. Reversed combustion may then be demonstrated in order to fully illustrate the reciprocal character of the phenomena. Thus it is ascertained that all ordinary cases of combustion are changes in which the air, and not the air as a whole but a particular constituent, is concerned, and no doubt remains that the same constituent is always active, but active under different conditions; it is realized also that the production of heat is the consequence of the union of the substance burnt with the active substance in air. The experiment of exposing phos. phorus in air affords the opportunity of demonstrating the evolution of heat even in a case where no visible combustion occurs, as the phosphorus is always observed to melt. At this stage careful note should be taken of the appearance of the different products of combustion, and of a change such as that which occurs when the product from phosphorus is exposed to the air.

Problem III. To separate the active from the inactive constituent of air.-It now has become of importance to get this active constituent of the air by itself, and the question arises whether it cannot be separated from one of the metals or other substances with which it has been found to combine. The pupil is therefore told to collect information about the different substances formed by burning metals, \&c.,--whether they can be obtained in sufficient quantity to work with, \&c. Iron rust and iron scale are easily obtainable, and so is copper scale; zinc is burnt to produce zinc white, which is used as paint ; lead is also burnt on a large scale, and in this case it appears that one or other of two substances is formed-litharge at a high temperature, red lead at a lower temperature. This peculiarity of lead suggests the study of the two products in the hope of discovering the clue to a method. Weighed quantities of the litharge and red lead are heated; it is observed that only the latter changes in appearance and that it loses weight. But what does it lose? It was formed by merely roasting lead in the air, and the some. thing which it loses must therefore have been derived from the air. If the red lead is heated in a tube a gas is given off which is collected and tested-how? With a taper or glowing splinter as it is to be supposed that the gas will support combustion if, as is to be expected, it is the active constituent of air. The discozery of the active constituent of air is thus made! If air consist of this gas and that which remains after exp sing phosphorus or iron in air, then by adding to such residual air as much of the gas from red lead as was withdrawn, air should be re obtained; this is found to be the case. The names of the two gases are now for the first time stated, and an easy method of preparing oxygen is demon-tsated, such as that of heating chlorate, but without any explanation. The conclusion previously arrived at, that probably in all the cases previously studied of changes occurring in air, the oxygen is the active substance, may now be verified by burning or heating in oxygen the substances which had been burnt in air.

So much having been learnt of the chemistry of air, the study of the pressure exercised by air may next be taken up, and the common pump, the force pump, the harometer, and air currents may be discussed and explained. Nowadays the charts given in the daily papers, and the Ben Nevis and glycerine barometer readings quoted in the Times make it particularly easy to explain the barometer. The pupils should be led to make barometer curves.

Probtem IV. To determine the composition of chalk.-The discovery of the composition of the air in the course of experiments made with the object of determining the nature of certain changes naturally suggests that the attempt be made to ascertain the composition of other things by studying the changes which they undergo. Chalk is known to give lime when burnt, and experiments made in Stage III. have indicated that chalk loses. something when burnt-the idea that an invisible something is given off is especially probable after the experiments with red lead have been made; so it is decided to heat chalk strongly, but before doing this chalk and lime are examined comparatively. Chalk is not observed to be altered by water; on shaking it up with distilled water and evaporating some of the filtered liquid in a weighed dish, very little residue is obtained-so it is established that it is but very slightly soluble in water. Lime is slaked, weighed quantities of "ne and water being used; the retention of a considerable amount of water, even after exposing the slaked lime in a drying oven, shows that the slaking involves a definite change in composition-that slaked lime is lime and water. The solubility of the lime is next determined, and found to be considerably greater than that of the chalk. It is found that chalk is but very slightly altered in weight when heated over a gas flame, and that it is only when it is strongly heated that it is converted into lime: so the chalk is strongly heated in an iron tube in a Fletcher blow-pipe furnace, when gas is freely given off. This is tested with a taper, which it extinguishes, so it cannot be oxygen, but may be nitrogen ; if it be nitrogen, when mixed with oxygen in the proportion of $\mathbf{I}$ to 4 , it should give air, but this is found not to be the case; so evidently it is a peculiar gas, and may be called chalk gas. If chalk consist of this gas and lime it should be possible to reproduce chalk from them; so the gas is passed through a small weighed tube containing lime, and the tube is found to get heavier. But lime and chalk are so much alike that it is difficult to say that chalk is formed ; perhaps dissolved lime will act similarly ; the gas is therefore passed into or shaken up with lime water. The precipitate which forms looks like chalk and probably is, but this rernains to be decided. The discovery of this behaviour of chalk gas, however, is important as affording a means of again comparing the gas from chalk with nitrogen. In working with lime water it is scarcely possible to avoid noticing that a film forms on its surface; by exposing a quantity of the lime water a considerable amount of the precipitate is obtained; its resemblance to chalk is noted, and the possible presence of chalk gas in air is thus suggested; but in view of the absence of proof of the identity of the precipitates with chalk a decision is reserved. The discovery is made, however, that air contains something besides oxygen and nitrogen.

It being thus establi-hed that chalk consists of two things, lime and chalk gas, at this stage it is pointed out how firmly these two constituents hold to each other in the chalk. The absorption of the gas by the lime-its entire disappearance in fact-is commented on. Accurate determinations of the loss of weight on heating crystallized chalk (calc-spar) should at this stage he carried out before the class, if not by the pupils, so that the numbers may be quoted and that it may become impressed on them that the proportions in which the lime and chalk gas are present is constant. Their attention may be recalled to the oxides previously studied, it being pointed out that on inspectio: these afford no indication that they contain oxygen; that here again the gas entirely loses its individuality on entering into union or combining. That oxides contain their constituents in fixed proportions may be demonstrated experimentally by oxidizing finely-divided copper and determining the increase in weight, lime being used as drying agent. In this way the 
characteristics of compounds are elucidated. Then the comparison may be made with air, and the fact made clear that it behaves as a mere mixture. Still no reference should be made to elements.

Problem V. To determine what happens when organic substances are burnt. - The experiments thus far made have shown that phosphorus and a number of metals burn in the air because they combine with the oxygen, forming oxides, heat being given out as a consequence; but that chalk when burnt is split up or decomposed into lime and chalk gas, this result being a consequence of the heating alone, the air having nothing to do with it. It remains to ascertain what happens when organic substances are burnt, as these give no visible product beyond a little ashes. As in all cases when vegetable or animal sub. stances are burnt a certain amount of "char" is obtained, which then gradually burns away, charcoal or coke is first studied. It having been discovered that the oxygen in air is the active cause of burning in many cases, it appears probable that the air is concerned in the burning of charcoal, coal, \&c. As when once set fire to, these continue to burn, the charcoal is at once heated in uxygen : it burns, but no visible product is formed ; it therefore follows that if the charcoal is oxidized the oxide must be an invisible gas. How is this to be tested for? What gases are already known to the pupil? How are these distinguished? Oxygen is excluded. Is it perhaps nitrogen, and is not perhaps the nitrogen in air merely used-up oxygen as it were, produced by the burning of organic substances? Or is it perhaps that gas which was found in the air along with oxygen and nitrogen, and which turned lime water turbid? This last being an easy test to apply is at once tried; the lime water is rendered turbid, and so to leave no doubt a sufficient amount of the gas is prepared and passed into lime water, the precipitate is collected, and the loss it suffers on heating is determined and found to agree with that suffered by the precipitate prepared from chalk gas. Finally, to ascertain whether the product is really heavier than the charcoal burnt, as in the case of the metals previously studied, the charcoal is burnt in oxygen in a tube connected to 2. flask containing milk of lime with a lime-drying tube attached to it ; the tube is weighed before and after burning. Thus the discovery is made that chalk gas is an oxide of carbon, and that chalk con'sists of at least three things.

It may be objected that to make the experiment in this manner takes too much time; but to this it may be answered that such experiments are precisely of the kind of those made in actual practice, and that they exercise a most important influence in teaching the pupils to take nothing for granted, never to jump at conclusions, and to rest satisfied if they progress surely, however slow the advance may be.

A number of organic substances may now be burnt, and the gas passed into lime water; chalk gas is found in every case to be a product, and hence the presence of a common constituentcarbon-in all is established. In making these experiments the formation of a liquid product is observed, so it is evident that chalk gas is not the only product, or carbon their only constituent.

Food materials generally having been found to contain "carbon," as they are obviously in some way destroyed within the body, and it is known that air is necessary for life, the question arises, what becomes of food, and why is air necessary for life? Is the food, perhap;, in large part "burnt up" within the body, thus accounting for the fact that our bodies are always warm? The characteristic product of combustion of carbonaceous substances is therefore tested for by breathing into lime water. The discovery thus made affords an opportunity for a digresion and for explaining how plants derive their carbon from the air.

- Pronlem VI. To determine what happens when sulphur is burnt.-From the results of the experiments with carbon, it appears prubable that the disappearance of sulphur when burnt is also really due to its conversion into a gaseous oxide, so it is kindled and introduced into oxygen : if it be burnt over water in a bell jar in a spoon passing through the stopper (a rubber cork), the water is seen to rise; if, on the other hand, it be burnt in a dry flask closed by a rubber cork carrying a gauge-tube, as suggested by Hofmann, ${ }^{1}$ the volume is seen to be almost un. changed after combustion. It foll sws, therefore, that the sulphur and oxygen unite and form a soluble product. Sulphur is next

${ }^{x}$ By burning carbon also in this way a most effective demonstration is given of the fact that no loss or gain of matter attends the change, and that only heat escapes; the results in the case of carbon and sulphur are particuarly striking, as the products are gaseous and invisible. burnt in a tube in a current of oxygen, and the gas is passed into water; a solution is thus obtained having the odour of the gas and sour (acid) to the taste. The fact that carbon and sulphir -both non-metals-behave alike in yielding gaseous oxides suggests that a comparison be made of their oxides; so the acid solution is added to lime water; a precipitate is formed, which redissolves on adding more of the sulphur gas solution; on the other hand, on adding the lime water to the acid liquid, this latter after a time loses its characteristic smell. There can be no doubt, therefore, that the sulphur gas doe; in some way act upon the lime. The experiment is then made of burning the sulphur in a weighed tube containing lime; the weight increases, so that no doubt remains that sulphur, like carbon, forms an oxide when burnt. The discovery that the addition of more of the sulphur oxide leads to the dissolution of the precipitate which it first forms in lime water, suggests trying the effect of excess of the carbon oxide on the lime water precipitate; this is done, and the discovery is made that the precipitate gradually dissolves. The solubility of the ne: substance may then be determined by passing the gas into water containing chalk in suspension, filtering, and evaporating. This leads to the observation that a precipitate is formed on heating the liquid, and this is soon found to be chalk. An opportunity is thus afforded of explaining the presence of so much "chalk" in water; of demonstrating its removal by boiling and by lime water; and the effect it has on soap.

The observation that the oxides of both carbon and sulphur combine with lime suggests trying whether the one will turn out the other; so the solution of the sulphur oxide is poured on to chalk : effervescence is observed, and on passing the gas into lime water a precipitate is obtained. The production of this effect by the acid solution suggests tryin $r$ comm on vin 2 gar-a well-known acid substance. This also is found to liberate chalk gas, and the discovery of an easy method of preparing chalk gas is thus made. The oxide formed on burning phosphorus, having previously been found to give an acid solution, is tried, and it is found that it also liberates chalk gas. As a good deal of vinegar is found to give very little chalk gas, the question arises, Are there not acids to be bought which will have the same effect and are stronger and cheaper? On inquiry it is found that sulphuric acid or oil of vitriol, muriatic acid or spirits of salts, and nitric acid or aquafortis may be bought, and that these all act on chalk. The behaviour of chalk with acids affords a means of testing the lime water precipitate obtained in working out Problems IV. and $V$. In this manner the pupil is led to realize that certain agents may very readily produce effects which are only with difficulty produced by heating - that the chemical agent may produce very powerful effects. The ready expulsion of the carbon oxide of chalk suggests that other substances not yet studied, such as the metals, when treated with acids may behave in a special manner which will afford information as to their nature. At this point, prior to making the experiments with the acids, an explanation may be given of the names oil of vitriol, spirits of salts, and aquafortis; the processes by which they are made may be described and illustrated, without, however, any attempt being made to explain them from the chemical point of view. The sulphuric acid should be made from green vitriol, and its behaviour on dilution should be demonstrated as well as its use as a drying agent.

PROBLEM VII. To determine what happens when metals are heated with acids. -Iron, zinc, lead, tin, copper, and silver may be taken. On pouring diluted oil of vitriol on to iron or zinc, the metal dissolves with effervescence ; the gas is collected, and when tested is found to burn. Thus a new gas is discovered, differing from all which have previously been studied, inasmuch as it is combustible; in order not to interrupt the study of the action of acids on metals, however, its further examination is postponed for a while. Resuming the experiments with metals, lead, tin, copper, and silver are found not to be acted upon by diluted oil of vitriol.

Muriatic acid, in like manner, dissolves iron and zinc and also tin with effervescence, and the gas which is given off in each case exhibits the same behaviour as that obtained from iron or zinc and diluted oil of vitriol. Lead, copper, and silver are not appreciably affected.

Aquafortis is found to dissolve not only iron and zinc but also copper, lead, and silver, and to convert tin int, a white substance - to attack all the metals in fact, thus justifying its name. The gas which is given off as the metal dissolves is observed to be coloured; when it is collected over water, however, it is seen to 
be colourless, and to become coloured on coming into contact with air-oxygen and nitrogen are, therefore, added to portions of the gas over water. In this manner, not only is a new gas discovered, but also a test for oxygen; and opportunity is afforded of here calling attention to the fact that air behaves exactly as oxygen, that the oxygen in air appears to be unaffected by its association with nitrogen-that, in fact, it is uncombined. From these experiments it is obvious that metals and acids interact in a variety of ways. Finally, the dissolution of gold and platinum by aqua regia may be demonstrated.

ProBlem VIII. To determine what happens when oxides are treated with acids. - In the course of the previous experiments a number of oxides have been prepared by burning various metals in air ; these are found to be unchanged by water. The discovery that acids act on metals suggests a trial of the effect which acids will have on their oxides; so the oxides of zinc, iron, copper, and lead are submitted to the action of the three acids previously used. Sulphuric acid is found to dissolve zinc oxide, iron rust, and copper oxide, but no gas is evolved ; excess of the oxide may be used, and the filtered liquid concentrated the crystals which separate may be examined and compared with those obtained by dissolving the metal in sulphuric acid, \&c. Litharge apparently is not changed by sulphuric acid, but red lead is, although not dissolved. Muriatic acid being used, all the oxides are found to dissolve, and in the case of red lead a greenish-yellow gas is given off possessing a most disagreealble smell : this is noted as a case for study. The product from the lead oxides is observed to crystallize out from the hot liquid on standing, so the undissolved original product is boiled up with water, and the solution is filtered, \&c. Attention is thus directed to the difference in solubility of the products. Next, aquafortis is userd; again all are dissolved, except the red lead, which, however, is obviously altered. In the case of the lead oxides the product is again less soluble than those afforded by the other oxides, but more soluble than the product obtained on using muriatic acid. The pupil has already been led to realize that of two substances capable of acting on a third, such as chalk gas and sulphur gas, which both combine with lime, one may be the stronger, and may turn out the other, sulphur gas turning out chalk gas from chalk. A comparison of the three acids with the object of ascertaining which is the strongest is therefore suggested : the metal or oxide is dissolved in one of the acids, and the others are then added. No positive result is obtained in case of zinc, iron, or copper, but the solution of lead in nitric acid is precipitated by muriatic and by sulphuric acid ; the former precipitate is found to dissolve in boiling water and to crystallize out in exactly the same way as the substance obtained from lead oxide and muriatic acid. The sulphuric acid product is found to be almost insoluble in water, and also in muriatic and nitric acids : these observations make it possible, by examining the behaviour towards muriatic and nitric acids of the products of the action of sulphuric acid on the learl oxides, to establish the fact that the product is the same whether lead be dissolved in nitric acid and sulphuric acid be then added, or whether either of the oxides be treated with sulphuric acid. It is further evident that those acids which give difficultly soluble or insoluble products act with difficulty if at all on the metal. Other metals besides those mentioned may be now studied, and, a solvent being found, the acids which do not dissolve the metal may be added to the solution. In this way, for example, the chloride test for silver is discovered.

In experimenting with acids the pupils can hardly fail to stain their clothes and their fingers. The observation that acids alter colours serves to suggest experiments on the action of acids on colours, especially those of leaves and flowers. The use of litmus, methyl-orange, cochineal, \&c., may then be explained. As various oxides have been found to "neutralize" acids, the study of their effect on the colours altered by acids is suggested. Lastly, a few experiments with vegetable and animal substances, sugar, \&c., may be made, which demonstrate the corrosive action of oil of vitriol and aquafortis.

PROBLEM IX. To determine what happens when the gas obtained by dissolving iron or zinc in sulphuric or mul iatic acid $i$ burnt. - The gas has been observed to burn with a smokeless, odourless flame. To ascertain whether, as in all other cases of combustion previously studied, the oxygen of the air is concerned in the combustion, a burning $\mathrm{jt} t$ of the gas is plunged into a dry cylinder full of oxygen, in which it is not only seen to continue burning, but it is also noticed that drops of liquid condense on the cylinder above the flame; this im- mediately suggests that the product is a liquid. The jet is found to be extinguished in nitrogen, so evidently when the gas burns it forms an oxide. The experiment is repeated, and the gas burnt in a bell jar full of oxygen over water: the water rises as the combustion proceeds, proving that the oxygen is used up. To collect a sufficient quantity of the product for examination, the dried ${ }^{1}$ gas is burnt at a jet underneath a Florence flask through which a stream of cold water is allowed to circulate : the neck of the flask is passed through the neck of a bell jar and the flask and bell jar are clamped up in an inclined position, so that the liquid which condenses may drop into a small beaker placed below the rim of the jar. What is the liquid? It locks very like water, and is without taste or smell. Is it water? How is this to be ascertained? What are the properties of water? The knowledge previously gained here becomes of importance. It has been observed that frozen water melts at $0^{\circ} \mathrm{C}$., that water boils at $100^{\circ}$, and that one cubic centimetre weighs one gramme at $4^{\circ} \mathrm{C}$.; so the liquid is frozen by the icemaker's mixture of ice and salt, a thermometer being plunged into it so that the solid ice forms on the bulb: the melting-point is then observed. Subsequently the boiling-point is determined, a little cotton-wool being wrapped around the bulb of the thermometer. Lastly, the density of the liquid may be determined. It is thus established that the gas yields water when burnt, and the name of the gas may now for the first time be mentioned and explained. The results thus obtained leave little doubt that water is an oxide of hydrogen; but in order to place this beyond doubt it is necessary to exclude nitrogen altogether. How is this to be done? Red lead is known to consist of lead and oxygen only, and readily parts with a portion at least of its oxygen; so dried oxygen is passed over red lead, which is then gently heated. Again a liquid is obtained which behaves as water, so there can be no doubt that water is an oxide of hydrogen. Water is not obtained on merely mixing. oxygen and hydrogen; it is only produced when combustion takes place. To start the combustion a flame is applied to a small quantity of a mixture of the two gases: a violent explosion takes place. An opportunity is here again afforded of calling attention to the entire change in properties which takes place when the compound is formed. On heating red lead in hydrogen, lead is obtained, although on heating it alone it loses only a portion of its oxygen, and the "reduction" takes place very readily; evidently, therefore, hydrogen is a powerful agent. This observation suggests further experiments. Will it not be possible to remove oxygen by means of hydrogen from other oxides which are not altered on heating? and will not other combustible substances besides hydrogen remove oxygen from oxides?

Problem X. To determine what happens when hydrogen and other combustible substances are heated with oxides. - Zinc oxide, iron rust, and copper oxide are now heated in a current of hydro gen: the first remains unaltered, the other two are seen to change, a liquid being formed which it cannot be doubted is water; the copper oxide evidently becomes reduced to copper. Is the iron rust similarly reduced to the metallic state? How is iron to be tested for? Iron is attracted by the magnet, and dissolves in diluted oil of vitriol with evolution of hydrogen. Applying these tests, no doubt remains that the iron rust is deprived of its oxygen.

Litharge and copper oxide may then be mixed with soot or finely powdered charcoal and heated in tubes; gas is given off which renders lime water turbid, and metallic lead or copper is obviously obtained. It is thus established that some but not all oxides may be deprived of their oxygen by means either of hydrogen or carbon. Opportunity is here afforded of explaining the manufacture of iron.

Several dried combustible organic substances, sugar, bread, and meat, may now be burnt with copper oxide in a tube the fore part of which is clean and is kept cool : liquid is seen to condense, while "chalk gas" is given off; the liquid has the appearance of water, and sufficient may easily be obtained to ascertain whether it is water. The presence of hydrogen in organic substances is thus discovered ; its origin from water may now be explained, and the double function of water in the plant and animal economy may be referred to--viz. that it both enters into the composition of the animal and plant structure and also acts as a solvent. The combustion of ordinary coal gas, of alcohol, of petroleum, of oil and of candles, may then be

1 The importance of crying the gas is realized without difficulty, as previous observations have shnwn that the air is moist, and as the gas is given off in presence of water, lime may be used. 
studied, and the presence of hydrogen in all of these noted.

PROBLEM XI. To determine whether oxides such as woter and chalk gas may be deprived of oxygen by means of metals. It being found that hydrogen and carbon withdraw the oxygen from some but not from all metals, it follows that some metals have a stronger, others a weaker, hold upon or "affinity" to oxygen than has either hydrogen or carbon; the question arises whether any and which metals have so much greater an affinity to oxygen that they will withdraw it from hydrogen and carbon. Copper and iron have been found to part with oxygen, but zinc and magnesium did not, so these four metals may be studied comparatively. Steam is passed through a red-hot copper tube full of copper tacks : no change is observed. The experiment is repeated with an iron tule charged with bright iron nails : a gas is obtained which is soon recognized to be hydrogen, and on emptying out the nails they are found to be coated with black scale. Zinc and then magnesium are tried, and, like iron, are found to liberate hydrogen. Chalk gas is next passed over redhot copper, and is found to remain unchanged, but on passing it over red-hot iron or zinc a gas is obtained which burns with a clear blue smokeless flame : this gas is not absorbed by milk of lime, but on combustion yields chalk gas, so it evidently contain carbon, and is a new combustible gas. Like hydrogen, it is found to afford an explosive mixture with oxygen. Finally, magnesium is heated in chalk sas : it is observed to burn, and the magnesium to become converted into a blackish substance unlike the white oxide formed on burning it in air. But it is to be expected that this oxide is produced, and to remove it, as it is known from previous experiments to be soluble in muriatic acid, this acid is added : a black residue is obtained. What is this? Is it not probable that it is carbon? If so, it will burn in oxygen yielding chalk gas. So the experiment is made. These experiments in which hydrogen is obtained from water and carbon from chalk gas afford the most complete "analytic" proof of the correctness of the conclusions previously arrived at regarding water and chalk gas, and which were based on "synthetic" evidence; taken together, they illustrate very cleariy the two methods by which chemists determine composition.

As hydrogen and carbon form oxides from which oxygen may be removed by means of some metals but not by all, the question arises, Which has the greater hold upon or affinity to oxygen -carbon or hydrogen? As it is the easiest experiment to perform, steam is passed over red-hot charcoal: a combustible gas is obtained which yields water and chalk gas when burnt, so evidently the hydrogen is deprived of its oxygen, and this latter combines with the carbon, forming the combustible oxide of carbon. Will not carbon partly deprive chalk gas of its oxygen? The experiment is made and it is found that it will. These results afford an opportunity of calling attention to and explaining the changes which go on in ordinary fires and in a furnace.

ProniEm XII. To determine the composition of salt gas, and the manner in which it acts on metals and oxides. - It has previously been demonstrated that spirits of salt or muriatic acid is prepared by acting on salt with oil of vitriol and passing the gas which is given off into water; the solution has been found capable of dissolving various metals and oxides, chalk, lime, \&c., and as water alone does not dissolve these substances the effect is apparently attributable to the dissolved gas, so it becomes of interest to learn more of this gas in order that its action may be understood. It is first prepared; its extreme solubility in water is observed, and also the fact that as it dissolves much heat is given out; and it is noted that although colourless and transparent it fumes in the air. How is its composition to be determined? Is there any clue which can be followed up? Reference is made to the previous observations, and it is noted that its solution dissolves various metals with evolution of hydrogen; water alone has no such effect. Is this hydrogen derived from the water or from the dissolved gas? The gas alone is passed over heated iron turnings, and the escaping gas is collected over water: it proves to be hydrogen, so evidently salt gas is a compound of hydrogen with something else. How is this something else to be separated from th hydrogen? Do not previous experiments suggest a method? Yes, they have proved that hydrogen has a marked affinity to oxygen, and now it is recollected that on treating muriatic acid with red lead-a a substance rich in oxygen-a greenish-yellow gas is obtained. The experiment is repeated on a larger scale and the gas is examined. If it is contained together with hydrogen in salt gas, perhaps salt gas will be obtained on applying a flame to a mixture of the two gases just as water is from a mixture of oxygen and hydrogen : the mixture is made and fired, and the result leaves little doubt that salt gas does consist of hydrogen in combination with the greenish-yellow gas-chlorine. Whence is this chlorine derived-from the salt or the sulphuric acid?

The notes are again consulted, and it is seen that a solution of silver in nitric acid gave a characteristic precipitate with muriatic acid but not with sulphuric, so salt solution is added to the silver solution, and a precisely similar precipitate is obtained, leaving little doubt that the chlorine is derived from the salt. It is now easily realized that the iron and zinc displace the hydrogen of the dissolved hydrogen chloride. What happens when the oxides are acted on? In addition to the metal they contain oxygen, which is known to combine readily with hydrogen, forming water; is water formed? Lime oxide is therefore heated in hydrogen chloride; a liquid is obtained which behaves exactly as a solution of hydrogen chloride in water. When the action is complete, after driving off all that is volatile, a solid remains very like fused common saltdoubtless zinc chloride, as it is to be supposed that as the hydrogen has taken the place of the zinc the chlonine has taken the place of the oxygen. What, then, is the action of hydrogen chloride on chalk? It evidently not only separates the chalk gas from the lime, but al:o dissolves this latter. What is formed? Dry (unslaked) lime is therefore heated in a current of hydrogen chloride. It beilaves just as zinc oxide, yielding a liquid product-evidently a solution of hydrogen chloride in water, as it dissolves zinc with evolution of hydrogen, and the residue is like that of zinc chloride. The important discovery is thus made that lime also is an oxide-that chalk, in fact, is a compound of two oxides; the resemblance of lime to zinc oxide and magnesium oxide is so striking that the conclusion is almost self-evident that lime is probably a metallic oxide, and it may be here pointed out that this actually is the case. The gradual discovery of the composition of chalk in the manner indicated is an especially valuable illustration of chemical method, and serves to show how chemists are often obliged to pause in their discoveries and to await the discovery of new facts and methods of attack before they are able to completely solve many of the problems which are submitted to them. The solids obtained on dissolving zinc oxide and lime in muriatic acid and boiling down the solution, when all the water is driven off, are white solids like fused salt, but on exposure they gradually become liquid. In so doing they increase in weight, and evidently behave like sulphuric acid. Probably water is absorbed from the air: no change takes place when they are kept over sulphuric acid or dry lime. In this way two new desiccating agents are incidentally discovered.

PROBLEM XIII. To determine the composition of washing-soda. - The study of this substance is of importance as introdacing the conception of an alkali. The preparation from salt is fir:t described. On heating the crystals they melt and give off "steam"; the experiment is made in such a way that a quantity of the liquid is obtained sufficient to place beyond doubt that it is water. The water is found to be easily driven off on heating the crystals in the oven, and to constitute a very large proportion of the weight of the crystals. The conception of water of crystallization is thus gained. On heating the dried substance to full redness in the platinum, ish, no loss cccurs. The residue dissolves in water, and "soda crystals" may again be obtained from the solution, so that heat does not affect it. Perhaps acids. which have been found to act so powerfully in other cases will afford some clue. On trial this is found to be the case : a colourless, odourless gas is given off, which extinguishes a burning taper. Is this perhaps nitrogen or chalk gas? The lime water test at once decides that it is the latter. So it is determined that washing-soda, like chalk, is a compound of chalk gas-but with what? With an oxide? The dried substance is heated in hydrcgen chloride: chalk gas is given off as before, and a. liquid which is soon recognized as water saturated with hydrogen chloride. The residue dissolves in water, and separates from the concentrated solution in crystals exactly like salt, and, in fact, is soon recognized to be salt; evidently, therefore, that which is present in salt along with chlorine is present in soda crystals along with oxygen, chalk gas, and water. The preparation of the metal sodium from soda is then explained. Acquaintance being thus made with compounds of chalk gas with two different oxides, the question arises, which oxide has the 
greater affinity to tha chalk gas? Will lim ? displase sodium oxide from soda or vice virsâ? On adding lim? witer to sola solution, a precipitate of chalk is formed. Wuat does the solution contain? Lime water contains lime in conbination with water; is the solium oxide present in combination with water? Soda is boiled with millk of lime (in an iron sauce. pan to avoid breakage) until it no longer affects lime water; afterwards the liquid is poured off and boiled down. The product is very unlike soda: it is very caustic, and when exposed to the air becomes liquid. If it is an analogous substance to slaked lime, it should combine with chalk gas and ba reconverted into sola; this is f und to be the case. Caustic soda is thus discovered. Chalk and lime are known to neutralize acid; ; bo:h soda and caustic sola are found to do so, and their effect on vegetable colours is found to be the reverse of that of acids. At this stage the origin of the nam a alkali is explained, and it is pointel out that the oxides which have been studied may be arranged in two groups of alkali-like or alkylic and acid. forming or acidic oxides, the form ar being derive 1 from $m$ atals, the latter from non-metals. The production of salts by the union of an oxide of the one class with the oxide of the other class is then illustrated by reference to earlier experiments.

The point is now re:uched at which the results thus far obtained may be reconsidered. The student has been led in many cases to make discoveries precisely in the manner in which they were originally made; and it is desirable that at this stage, if not earlier, the history of the discovery of the composition of air and water, \&c., should be briefly recited. It is then pointed out thit a variety of substances have been analyzed and resolved into simpler substances-air into oxygen and nitrogen, water into oxygen and hydrogen, \&c.; and that these simpler subitance; thus far have resisted all attempts to further simplify them, and are hence regarded as elements. A list of the known elements having been given, the diverse properties of the elements may be illustrated from the knowledge gained in the course of the experiments. The fact that when elements combine compounds alto rether different in properties from the constituents are formed also meats with manifold illustratio.. Tos little has been ascertain ad to adm: of any general conclusion baing arrived at with regard to the proportions in whic's elements combine, but it is clear that they may combine in more than one proportion since $t w s$ oxides of carbon have been discovered, and in the only cases studiedviz. copper oxide and chalk - ihe composition has been found not to vary. The existence of variou; types of compounds has been recognized, and a good deal has been learnt with reference to the nature of chmmical change. B.tt, abjve all, the method of arriving at a knowledge of facts has been illustrated time after time in such a manner as to influence in a most important degree the habit of mind of the careful student. New facts have been discovered by the lo rical application of previously discovered facts : the logical use of facts, and the habit of using facts have been inculcated. This is all-important. It has become so customary to teach the facts without teaching how they have been discovered that the great majority of chemical students never truly leara the use of facts; they consequently pursue their daily avocation; in a perfunctory manner, and only in exceptional cases manifest th se qualities which are required of the investigator; their enthusiasm is not awakened, and they have little desire or inclination to add to the stock of facts. It must not for one $m>m e n t$ be supposed that the object of teaching chemistry in schools is to make all chemists. Habits of regulated inquisitiveness, such as m'x st gradually be acquired by all who in elligently follow a course such as has been sketched out, are, howe ver, of value in every walk of life; an 1 certainly the desire to un lerstand all that co nes under observation should as far as possible be implanted in everyone.

STAGE V.-The curntitalive stage.

The quan'itative compssition of many of the substances which have previously been stulied qualitatively should now be determinad-in some cases by the teacher in face of the papils, so that every detail may be observed and all the results recorded; in other cases by the pupils.

The composition of water is first determined by D 1 mas' method; this may easily be do re, and fairly accurate result; may be obtained in the course of a couple of hours. The results obtained by D umas and subsequent workers should then all be cited, and, attention having been drawn to the extent to which such exprriments are necessarily su'bject to error, the evidence which the results afford that hydrogen and oxygen combine in certain fixed and invariable proportions to form water is especially insisted upon.

The composition of chalk gas is next determined; this also is easily done, as impure carbon (lampblack) may be burnt and the hydrogen allowed for. Again, attention is directed to the results obtained by skilled workers, and the evidence which they afford that chalk gas never varies in composition.

The composition of copper oxide has already been ascertained; it may be re-determined by reducing the oxide in hydrogen : in fact, in determining the composition of water.

The lead oxides may be reduced in a similar manner, the oxide obtained by igniting white lead as well as red lead and the brown oxide obtained by treating red lead with nitric acid being used. In this way it is ascertained that the brown oxide is the highest oxide; the loss in weight whizh this oxide suffers when ignited may then be determined.

Tabulating the results thus obtained, after calculating with what amount of the particular element that quantity of oxygen is associated which in water is combined with one part by weight (unit weight) of hydrogen, numbers such as the following are obtained :-

I part of hydrogen is combined with 8 parts of oxygen in water.

3 parts of carbon are combined with 8 parts of oxygen in chalk gas.

$3 \mathrm{~T}^{\cdot} 5$ parts of copper are combined with 8 parts of oxygen in copper oxide.

I03.5 parts of lead is combined with 8 parts of oxygen in lead oxide (litharge).

5 I.8 parts of lead are combined with 8 parts of oxygen in lead oxide (brown)

These clearly illustrate the fact that elements combine in very different proportions, and the results obtained with the lead oxides afford also an illustration of combination in multiple proportion.

The amounts of silver and lead nitrates formed on dissolving silver and lead in nitric acid are next determined by evaporating the solutions of known weights of the metals in porcelain crucibles on the water-bath, and then drying until the weight is constant; accurate results may be easily obtained, ant these two exercises afford most valuable training. The nitrates are subsequently evaporated with muriatic acid and the weights of the products determined. What are these products? Does the metal simply take the place of the bydrogen in hydrogen chloride as zinc does when it dissolves in muriatic acid? If so, the products are silver and lead chlorides, and it may be expected that the same substances will be obtained-that the same increase in weight will be observed, when, say, silver is combined directly with chlorine as when it is dissolved in nitric acid and the solution is precipitated with muriatic acid or salt. Silver is, therefore, heated in chlorine, and is found to increase in weight to the same extent as when it is dissolved in nitric acid, Sc. ; a given weight of silver precipitated by salt is also found to increase to the same extent as when it is directly combined with chlorine. The composition of silver chloride having thus been ascertained, the amount of chlorine in salt is determined. The composition of salt being ascertained, purified dried washing-soda is converted into salt, and also the amount of chalk gas which it contains is determined : from the data, the composition of sodium oxide may be calculated. In like manner the composition of lime may be ascertained by converting chalk into chloride by igniting it in hydrogen chloride, and then determining the chlorine in the chloride; the same method may be applied to the determination of the composition of the oxides and chlorides of zinc, magnesium, and copper.

Discussing these various results, and comparing the quantities of oxygen and of chlorine which combine with any one of the metals examined, it is seen that in every case about $35^{\circ} 4$ parts of chlorine take the place of 8 parts of oxygen. Combination in reciprocal proportions is thus illustrated, and by considering the composition of chalk and washing-soda it may be shown that this applies equally to compounds of two and to compounds of three elements. As 354 parts of chlorine are found in every case to correspond to 8 parts of oxygen, it is to be expected that hydrogen chloride cont ins one part of hydrogen in combination with $35^{\circ} 4$ parts of chlorine; a solution containing a known weight of hydrogen chloride is, therefore, prepared by passing the gas into a tared flask containing water and the chlorine is then determined. 
It being thus clearly establisbed what are equivalent weights of elements, the conception of equivalen:s may be further developed by exercises in acidimetry carried out by the pupils themselves. The proportions in which washing-soda and hydrogen chloride interact may be determined by mixing solutions of known strength until neutralization is effected; if the solution be evaporated and the chloride weighed, the results may be used in calculating the composition of hydrogen chloride; they serve, in fact, as a check on the conclusions previously arrived at as to the composition of washing-soda and hydrogen chloride. Solutions of sulphuric and nitric acid may be similarly neut ralized, and, the amounts of sulphate and nitrate formed having been ascertained, the equivalents of the acids may be calculated on the assumption that the action is of the same kind as takes place in the case of hydrogen chloride. Determinations of the strengths of acids, \&c., may then be made. In a similar manner the volumetric estimation of silver may be taught, and the percentage of silver in coinage and other alloys determined

Such a series of quantitative exercises as the foregoing, when carried out before and to a considerable extent by the pupils, undoubtedly affords mental discipline of the very highest order, and is effective of good in so many ways that the value of such teaching cannot be over-estimated. The failure to grasp quantitative relationships which examiners have so frequently to deplore is without question largely, if not alone, due to students' entire ignorance of the manner in which such relationships have been determined. Moreover, the appreciation by the general public of the principles on which quantitative analysis is founded would undoubtedly be directly productive of good in a multiplicity of cases.

STAGE VI.-Studies of the physical properties of gases in comparison toith those of liquids and solids. The molecular and atomic theories and their application.

A series of quantitative experiments on the effect of heat on solids, liquids, and gases should now be made, and these should be followed by similar experiments on the effect of pressure; the similar behaviour of gases, and the dissimilar behaviour of liquids and solids, is thus made clear. The condensation of gases is then demonstrated and explained, and also the conversion of solids and liquids into gases, and the dependence of boilingpoint on pressure and temperature. Kegnault's method of determining gaseous densities is studied, and the method of determining vapour densities is illustrated. The molecular constitution of a gas is now discussed; the phenomena of gaseous and liquid diffusion are studied, and a brief reference is made to the kinetic theory of gases ; then Avogadro's theorem is expounded and applied to the determination of molecular weights; and eventually the atomic theory is explained, and the manner in which atomic weights are ascertained is brought home to the pupils. The use of symbols must then be taught. Finally, the classification of the elements in accordance with the periodic law should be explained.

It is all-important that at least a large proportion of the experiments in each of the stages should be made by the pupils; but even if this nere not done, and the lessons took the form of demonstrations, much valuable instruct:on might still be given.

The majority of pupils probably would not proceed to the fifth and sixth stages; but those who perforce must terminate their studies without gaining any knowledge of chemical philosophy should unfailingly be led to make a few simple quantitative experioents : for example, to deternine silver volumetrically, and the method of determining the composition of water and chalk gas should be demonstrated in their presence : and it may be added that, if only the examples in Stages I. and II. and Problems I. to V, of Stage III. were thoroughly worked out, most important educational training would be given, and much valuable information as to the nature of common phenomena would be gained.

The complete course would undoubtedly take up considerable time, but so does a satisfactory mathematical or classical course of study, and it is absurd to suppose that useful training in science is to be imparted in a few months. If instruction be given in the manner suggested at all generally, it will be necessary, however to modify the present system of testing results. Pupils could not be expected to pas at an early age examinations such as are at present held, and awards would have to be based chiefly on an inspection of the clases at work and of note-books and on vivâ voce questioning. But all are agreed that the present system of payment on results tested by a terminal examination is a most unhealthy one, and that a more rational system must be substituted for it. I may suggest that if members of the staf of science colleges, such as are now established in so many towns, could be appointed suternising inspectors, whore duty it would be to advise teachers in schools and occasionally to inspect the teaching in company with the fermanent inspector, it would be possible to secure the assistance of a body of men who are in touch with scientific progress and conversant with the imprcvements which are being $\epsilon$ ffected. A man who "once an inspecter is always an inspector" of necessity must get into a rut, and will escape from the wholesome leavening and rousing influence which is always more or less felt by those whose office it is to follow the march of scientific progress.

It should also here be pointed out that the great majority of the experiments and exercises described may be carried out with very simple apparatus, and with slight provision in the way of special laboratory accommodation. In but very few cases is there any production of unpleacant smells or noxious fumes. It is, in fact, a mistake to suppose that an elaborately fitted laboratory is in every case essential for successful teaching : much might be done in an ordinary schoolroom provided with a demonstration bench for the use of the teacher, a draught closet over the fire-place, a sink, a raised table for balances (raised so that the teacher might see what was going on), a cupboard for apparatus, and a long narrow bench provided with gas-burners at which, say, twenty pupils might stand, ten a-side. At present the Science and Art Department will not recognize "practical chemistry" unless it be taught in a laboratory fitted up in a certain specified manner, and their regulations are such as to enforce the provision of expensive laboratories in all cases where it is desired to obtain the grant. If greater latitude in fittings were allowed, more attention being paid to the character of the work done and less to the tools with which it is accomplished, probably much less money would be wasted by inexperienced school authorities in providing special laboratories, and there would be much grea! er readiness displayed to enter on the teaching of experimental science. The course which has been sketched out is one which doubtless might well be modified in a variety of ways according to circumstances. Thus many simple exercises in mechanics, in addition to those directly mentioned, might be introduced into Stage JJ., and the mechanical properties of common materials might be somewhat fuliy studied at this stage in districts where engineering trades are largely e:tablished, and where such knowledge would be specially valuable. In like manner the physical effects of heat on substsnces might be studied in Stage IIJ. instead of Stage VI. And there are other chemical problems and simple exercises besides those described which might be substituted for some of them, or included in the course.

Prohably, however, it would be found undesirable, if not impossible, as a rule, to continue the teaching of chemistry proper much, if at all, beyond the stage indicated in this scheme. Other subjects will have a prior claim should it ever be deemed essential to include in a comprehensive scheme of school education the elements of the chief physical and physiological sciences; it certainly is of primary importance to introduce at as early a period as possible the conception of energy, and to explain the mechanical theory of beat, so that later on it may be possible to discuss the efficiency of heat and other engines; and, until the laws of the electric current are understood, the subject of chemical change can never be properly considered.

In many cases, where it is convenient or desirable to continue the chemical studies, it probably will be advantageous as a rule that they have reference to specific (Jocal) requirements-e.g. to agriculture in schools in agricultural districts; to focd materials and physiology in the case of girls especially, \&c. But in any case more consideration must be paid in the future in schools where chemistry is taught to educational requirements-the teaching must have reference to the requirements of the general public; and it must be remembered that the college, not the school, is the place for the complete study of a stibject.

With the ohject of presenting in an available form information as to the position occupied by chemistry in Board and other fublic elementary schools, which are controlled either by the Education Defartment, Whitehall, or the Science and Art Departy ent, South Kensington, the Committee now present a report on the subject which has been prepared by Prof. Smithells. A consicieraticn of this statement will show that, as 
in the higher grade public schools, with which the Report of the Committee last year was chiefly concerned, the condition of the teaching in public elementary schools is far from satisfactory. As a rule chemistry is not taught on the proper lines. The pupils frequently receive the same kind of instruction in chemistry as they would at a later stage if they were preparing for a professional or technical career; consequently the subject has failed to provide that mental education which it should be the main object of elementary teaching to develop. It appears, too, that in many of these schools physical science has not hitherto been regarded as a necessary part of the educational scheme. It is essential that this state of affairs should be altered, and that physical science should occupy a more favourable position in the Education Code, and that its teaching should be more thoroughly controlled.

It is to be hoped also that the Education Department, as well at the Science and Art Department, South Kensington, will take steps to arrange a more efficient mode of inspecting science teaching than that at present in vogue, which can only be regarded as satisfactory from a purely statistical standpoint. Under the present system little or no control can be exercised over the science teaching, since the Whitehall inspectors are, as a rule, not qualified to form an opinion as to its value. There would seem to be no difficulty in obtaining the services of properly qualified persons to act as additional inspectors for the purpose of reporting on the character of the science teaching. It is probable that many of the professors and lecturers in University Colleges, and other educational institutions, might be willing to take part in such inspection, and it would thus become possible to maintain a high standard of excellence in the teaching.

\section{THE GEOLOGICAL PAPERS AT THE BRTTISH ASSOCIATION.}

$\mathrm{N}^{\mathrm{N}}$ Thursday morning the first business of Section $\mathrm{C}$ was to hear Prof. Milne's ninth Report on the earthquake and volcanic phenomena of Japan, in which a list of seventy-nine earthquakes occurring between June 1888 and March 1889 is given. After a paper by Dr. Naumann, which will be referred to later on, Mr. T. P. Barkas read a paper on footprints of four-, three-, and two-toed animals, discovered in Lower Carboniferous sandstones near Otterburn, of which he exhibited specimens. A paper by Mr. Mellard Reade reviewed the chief theories advanced to account for the Lower 'Triassic rocks, and advocates their formation by tidal action in straits, seas, and bays from the denudation of the rocks of the Channel, Mendips, Belgian coal-field, Pennine, and the Old ked of Herefordshire.

Friday's sitting opened with Dr. A. Geikie's paper on the age and origin of the crystalline schists of Norway. In the Trondhjem region ordinary sedimentary rocks, much disturbed, contain Lower and Upper Silurian fossils, and are underlain by basic lavas and tuffs, succeeded by grits, slates, and schists with black pyritous and carbonaceous beds. Traced southwards, the whole series becomes progressively more crumpled and crystalline until it passes into a group of twisted mica schists, in which, however, the pyritous shales, although converted into mica schists, are still recognizable. Specimens were exhibited to show every step of metamorphism from an amorphous igneous rock to a perfect schist, the change being sometimes visible in a hand specimen In Bergen the author confirmed the discovery of fossils by Dr. Reusch in a frilled mica schist or phyllite, proving that the regonial metamorphism in this area was of post-Silurian date. Mr. Marr followed with a description of the Skiddaw slates on the east side of Brownber, where quart $z$ veins have been intruded between the bedding planes, the rock has been contorted, and converted into a rock composed largely of mica and secondary quartz, and exhibiting ausweichumngsclivage, in fact a mica schist. Prof. Bonney contributed a paper showing that the limestones associated with crystalline rocks were coarsely crystalline as a rule, but that pressure often obliterated this coarse texture by crushing, and thus could only be appealed to as a minor agent in producing crystallization; a further paper by the same author dealt with the fossils obtained amongst the crystalline schists in the Val Canaria, Val Piora, Nufenen Pass, and Lulimanier Pass; he concluded that in the first two localities the relations of the rocks had been misunderstood, while in the last two the fossils were in a rock whose minerals were in a very tifferent state from those in the older crystalline schists. Mr.
Watts exhibited a collection of Belemnites from the rocks of the Lukmanier Pass. Dr. Hatch described potash and soda felsites from the Lewer Silurian of Ireland, which were ancient equivalents of the rhyolites and pantellerites of 10-day; and Mr. A. R. Hunt brought forward a view that the granites of Dartmoor and of the Chamnel were of pre-Devonian and probably Archæan age. Mr. Teall sent an interesting communication on the amygdaloids of the Tynemouth dyke, in which he summarized the history of the rock as follows: (I) development of granular aggregates of felspar allied to anorthite under plutonic conditions ; (2) addition of new felspar substance to these, giving them outward crystalline form ; (3) formation of lath-shaped felspars; (4) separation of augite ; (5) formation of vesicles probably due to relief of pressure when the magma rose into a fissure; (6) filling of come of these vesicles with interstitial matter which probably oozed into them from the surrounding liquid magma, as they are seen in all stages of filling ; $(7)$ consolidation of intersti. tial matter; (8) filling up of the rest of the vesicles with carbonates. Mr. Swan exhibited specimens of marble from Paros, and described the new and old quarries; and then the Section listened to an account from Dr. Fridijof Nansen of the geological bearings of lis journey across Greenland.

Greenland is covered by a shield of ice rising to a height of 9000 or 10,000 feet in the centre, where it probably covers an area of mountains and valleys, and not a table-land, reduced to a gently sloping surface, and even polished, by the wind. The only evidence of ice melting on the surface in the interior consists of thin ice crusts at varying depths. The enormous pressure of the ice mass forces it out partly as ice and partly as water melted by friction, thus giving rise to the rivers, which flow even in winter. The great rate at which the ice flows out into the fjords makes the author an advocate for the agency of ice in forming these features.

On Saturday, Prof. W. C. Williamson read a paper in which he acknowledged the help he had received from all parts of the world in acquiring specimens and slides of coal and mineral charcoal from many English, Welsh, and Scotch localities, as well as from Japan, New Zealand, America, Europe, Asia, and Australia. The inquiry was still proceeding, with a view to ascertain the nature and origin of this mineral charcoal, and to estimate the extent to which cryptogamic spores contributed to coal formation. Prof. Williamson futher stated that in Lygino. dendron Oldhamium, he added a fern to the other cryptogams in which exogenous growth took place, and announced what he termed another botanical heresy, that in the Carboniferous Lycopods the vascular bundle enlarged into a ring inclosing a medulla which enlarged pari passu with the ring. Prof. T, R. Jones reviewed the advancement made by himself and others to our knowledge of the Palæozoic Phyllopoda; and Dr. JohnstonLavis's Report onVesuvius was presented. This Report announces that Messrs. Philip and Son will shortly publish the map of Vesuvius; it further gives a diagram of the cone in 1887 and I886 (? I888), and three taken in January, May, and August, 1889 , so as to show the changes resultant on overtlows of lava, formation of fissures, and building of new cones. The Report concludes with a further account of the new railway tunnels in the Phlegraan Fields.

Further specimens of the peculiar coral-like structures from the limestone of Culdaff have been obtained by the Geological Survey, and some of these, with photographs, were exhibited to the Section by Prof. Hull. Some foreign palæontologists, judging from the photographs, regarded them as organic, and referred them to Favistella, but English palæontologists give only a hesitating assent to this view. Mr. Cameron described Kellaway's sand and doggers from exposures near Bedford, and $\mathrm{Mr}$. Vine described sixteen species of Stomatopora and Proboscina from the Hunstanton Red Chalk.

On Monday, Mr. Ussher's paper on the Devonian rocks of Britain was presented. He divided the rocks into three typical areas, in each of which they presented peculiar characters. In North Devon ihere are arenaceous deposits indicating shoal witer ; in South Devon the rocks are variable, with sporadic volcanic and coral deposits; while in Cornwall and Devon, west of Dartmoor, the succession, though much disturbed and faulted, consists chiefly of mud and slates. A table is given, correlating the principal divisions in these three areas with their Franco-Belgian and German equivalents. An important paper by Prof. Lebour and Mr. Marley, on the South Durham salt industry and the extension of the Durham coal-field, followed. The area of proved salt amount ed to at least twenty square miles, 